\title{
Ensino de programação para o ensino médio com App Inventor: Um relato de experiência extensionista através da colaboração interinstitucional
}

\author{
Andréa S. Bordin ${ }^{1}$, Cristiane Gonçalves Pinheiro', Nathan Nunes Vargas \\ Gonçalves $^{1}$, Jaline Gonçalves Mombach ${ }^{2}$, Paulo Silas Souza ${ }^{2}$ \\ ${ }^{1}$ Universidade Federal do Pampa (Unipampa) - Alegrete - RS - Brasil \\ ${ }^{2}$ Instituto Federal Farroupilha (IFFar) - Alegrete - RS - Brasil \\ andreabordin@unipampa.edu.br, cristianegpinheiro@bol.com.br, \\ nathanfernando97@gmail.com, jaline.mombach@iffarroupilha.edu.br, \\ psss 04 @outlook.com
}

\begin{abstract}
Activities of university extension have the potential to supply the demands related to the incentive of computational thinking in schools. This paper reports the collaboration experiences between two federal educational institutions in an extension project focused on teaching programming to students of public schools through the MIT App Inventor tool. The evaluation showed that the the proposal was well received by the students and that interinstitutional extension activities have a positive impact because they allow the sharing of knowledge and resources for the community benefit.
\end{abstract}

Resumo. Atividades de extensão universitária têm potencial para suprir as demandas relacionadas ao estímulo do pensamento computacional nas escolas. Este artigo relata a experiência de colaboração entre duas instituições federais de ensino em um projeto de extensão com foco no ensino de programação para alunos de escolas públicas através da ferramenta App Inventor. A avaliação da ação mostrou que a proposta foi bem recebida pelos alunos e que ações de extensão interinstitucionais possuem um impacto positivo pois permitem o compartilhamento de conhecimentos e recursos em prol do benefício da comunidade.

\section{Introdução}

Segundo Pereira Júnior et al. (2005), a inserção da informática nas escolas possibilitou a reinvenção do processo de ensino e aprendizagem trazendo consigo novas didáticas e possibilitando a expansão dos conhecimentos da computação nestes locais. Esse contexto torna propício a criação de projetos que estimulam a resolução de problemas através da programação. Projetos que exploram o ensino de programação nas escolas permitem que os alunos se tornem mais que apenas usuários de computadores, capacitando-os a desenvolver o pensamento computacional, entender e usar linguagens de programação na implementação de ideias que beneficiem a sociedade onde estão inseridos.

A extensão universitária, um dos pilares da educação superior, tem o potencial de suprir essa demanda pois possui como diretriz básica a interação dialógica com a 
comunidade, seja no movimento de levar o conhecimento até a sociedade, seja no de realimentar suas práticas acadêmicas a partir dessa relação dialógica. Dessa forma ações de extensão que introduzem o pensamento computacional através da programação atendem a uma demanda iminente nas escolas e também permitem que os membros da comunidade acadêmica envolvidos realimentem suas próprias práticas.

Projetos de extensão, que dialogam com a comunidade, necessitam de saberes e olhares diferenciados de forma a se equacionar a melhor solução para a situação-problema alvo da ação. Portanto, quando executados de forma colaborativa, tendem a trazer melhores benefícios para todos os envolvidos.

Este artigo relata uma experiência de colaboração entre duas instituições federais de ensino em uma ação de extensão que objetiva ensinar programação com a ferramenta App Inventor para alunos de escolas públicas do município de Alegrete-RS.

\section{A gênese}

Essa experiência originou-se da existência, nas referidas instituições, de projetos com o objetivo comum de ensinar programação para alunos de escolas públicas. O projeto de extensão Pampa Code, ofertado pela Universidade Federal do Pampa (Unipampa) tem como objetivo difundir o ensino e a prática de programação de computadores para alunos do ensino médio de escolas públicas de Alegrete - RS. Já o projeto CodIFicar, ofertado pelo Instituto Federal Farroupilha (IFFar), localizado na mesma cidade, visa ofertar oficinas para o ensino de programação nas escolas públicas da região com foco na educação básica.

No ano de 2016, os coordenadores dos projetos anteriormente mencionados tomaram ciência da existência desse objetivo em comum e propuseram uma ação de extensão conjunta focada no ensino de programação para dispositivos móveis Android com a ferramenta App Inventor desenvolvida pelo MIT (Instituto de Tecnologia de Massachusetts).

A motivação para o ensino de programação em tecnologia móvel se deu em função da popularização dos smartphones no Brasil e porque, de acordo com Vieira e Alves (2015), a escola precisa explorar as potencialidades dos smartphones como ferramenta pedagógica aliada ao desenvolvimento intelectual dos alunos. O App Inventor foi escolhido por ser uma ferramenta voltada à programação e criação de aplicativos que transforma a linguagem de codificação textual em blocos de construção simples e também já ter sido utilizado em outras ações, como as propostas por Ribeiro, Manso e Borges (2016) e Finizola et al. (2014).

\section{O desenvolvimento}

O desenvolvimento conjunto desta ação de extensão compreendeu atividades de planejamento, divulgação, execução e avaliação. $\mathrm{Na}$ fase de planejamento foram realizadas reuniões para definir o formato e o local de oferecimento da oficina, os critérios de escolha da escola de ensino médio e o treinamento da equipe executora na ferramenta App Inventor. Optou-se pelo formato de oficina de curta duração com seis horas dividida em dois encontros de três horas na mesma semana. A partir do formato foram definidos os tópicos abordados, o tempo de cada atividade e quem seria o responsável por ministrar tal atividade. Definiu-se que a oficina seria ofertada nos 
laboratórios da Unipampa, para possibilitar que os alunos conhecessem o ambiente acadêmico. Os critérios para escolha da escola levaram em conta a proximidade com a universidade, dessa forma a Escola Estadual de Educação Básica Dr. Lauro Dornelles, localizada em frente à Unipampa, foi escolhida.

$\mathrm{Na}$ fase de divulgação, o projeto e a equipe envolvida, composta por 4 discentes de graduação ( 2 de cada instituição) e dois docentes (1 de cada instituição), foram apresentados aos alunos e professores da Escola. Após a divulgação obteve-se um total de 25 alunos inscritos, dos quais foram selecionados 21 alunos, através do critério de melhor resposta para a pergunta "Por que você deseja fazer essa oficina?".

\subsection{Primeiro encontro}

O primeiro encontro teve a presença de nove alunos e foi dedicado à explicação de conceitos básicos como o que é programação, extensões de arquivos (.apk), código Quick Response (QR) e como realizar buscas de imagens com direitos de uso marcadas para reutilização no Google. Os alunos tiveram contato com a plataforma App Inventor, houve a explicação sobre o funcionamento dos principais recursos da ferramenta e elaboração de um aplicativo simples composto por uma caixa de entrada e um botão para que ao receber um nome fosse mostrado uma notificação na tela do dispositivo.

Observou-se que as opções de personalização dos aplicativos (troca de cores, modelos de botão, organização dos elementos e inserção de imagens) foram as mais atrativas aos participantes. Por fim, foi proposta uma tarefa de prototipação, a ser realizada até a data do próximo encontro, na qual foram distribuídas folhas impressas com desenho de telas de smartphone onde os alunos deveriam planejar um aplicativo de perguntas e respostas, popularmente conhecido como "Quiz".

\subsection{Segundo encontro}

O segundo encontro foi dedicado à elaboração do aplicativo de perguntas e respostas e contou com a presença de três alunos. Revisou-se os conceitos apresentados no encontro anterior e explicou-se, passo a passo, como adicionar mais telas no aplicativo e também a configurar o uso de sensores (por exemplo, acelerômetro e sensor de proximidade). A partir disso, os participantes envolveram-se na construção de seus aplicativos guiados pelo protótipo desenvolvido.

A Figura 1 exibe registro fotográfico da atividade. Ao final do encontro, organizou-se uma roda de conversa para os alunos apresentarem suas criações e também avaliarem a oficina oferecida. Ademais, os participantes responderam a um formulário para avaliar as atividades, a equipe e os aplicativos.

\section{Resultados e Discussão}

No último encontro da oficina a ação foi avaliada por meio de um questionário de satisfação com escala de cinco itens, variando de Péssimo a Ótimo, composto por questões que avaliavam a equipe, o planejamento das atividades e o projeto como um todo. O questionário foi respondido por três participantes da oficina. 

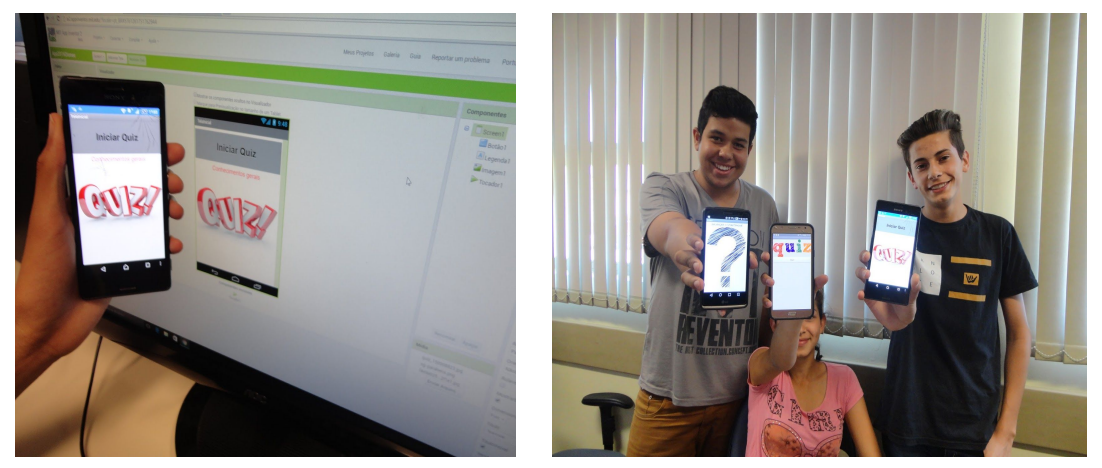

Figura 1. Registros da ação de extensão.

Em relação à avaliação da equipe, todos responderam a opção Ótimo, complementando com as seguintes respostas: "Eles foram muito atenciosos, explicam muito bem", "Me instruíram bastante" e "Super atenciosos, legais, explicaram muito bem". Quanto ao planejamento das atividades, todos também escolheram o item Ótimo e adicionaram os seguintes comentários: "Muito Boas", "Tive oportunidade de aprender algo que me chama bastante atenção" e "Ótimas, muito proveitosa".

As perguntas relacionadas ao projeto foram de resposta aberta: "O que foi mais legal no projeto?" e "O que não foi tão legal no projeto?". A primeira pergunta teve como resposta "Tudo foi muito legal", "Não teve algo 'mais legal' tudo foi mt legal" e "Tudo foi legal". A segunda pergunta teve como respostas: "Não teve nada ruim", "Acho que foi poucas oficinas" e "Tudo foi legal". Na última pergunta foi solicitado sugestões, que foram as seguintes: "Poderia ter mais aulas porque gostei muito" e "Nenhuma". A hipótese da equipe para o baixo número de participantes no segundo encontro foi o fato dela ter sido realizada no mês de dezembro e a escola já estar no período inicial de férias escolares.

A ação também foi avaliada pela equipe executora do projeto. Os discentes mencionaram que a experiência despertou e aumentou a vontade de tornar-se professor e proporcionou benefícios pessoais, como a diminuição da timidez e o aumento da confiança em falar em público, e que também propiciou a oportunidade de aprender uma nova forma de entender e explicar programação. Os docentes observaram um grande comprometimento da equipe discente durante o planejamento e execução da ação, o vencimento da dificuldade de falar em público, assim como a assimilação de algumas práticas didáticas que foram repassadas antes e durante a execução dos encontros.

O planejamento da oficina no formato de construção de aplicativo de perguntas e respostas (Quiz) também se mostrou efetivo, pois permitiu que num curto espaço de tempo os alunos aplicassem os principais conceitos e conseguissem criar, compilar e rodar uma app em seus dispositivos móveis. A execução da ação de extensão de forma conjunta pelas duas instituições permitiu que os esforços fossem divididos e os recursos fossem compartilhados.

\section{Conclusões}

A experiência com essa ação demonstrou que existe a necessidade e um amplo espaço 
de oportunidades para projetos que objetivem estimular o pensamento computacional através da programação em escolas públicas do município. Em Alegrete - RS, as instituições envolvidas neste relato são pioneiras neste tipo de iniciativa.

No entanto, percebe-se que projetos de extensão podem ser onerosos em termos de responsabilidade, tempo e recursos dispendidos em função de dialogarem com a comunidade. Essa ação demonstrou que esse ônus pode ser diminuído ou extinguido com a colaboração entre instituições que possuam projetos com objetivos em comum. Existem benefícios evidentes que podem servir de estímulo ao fomento da colaboração interinstitucional em projetos dessa natureza, tais como o compartilhamento de recursos materiais (materiais de divulgação, transporte, laboratórios, etc) e humanos (docentes e discentes). Em relação a este último, entende-se que o envolvimento de mais pessoas de IES diferentes possibilita uma intensa troca de conhecimentos e interação que beneficia a todos os envolvidos.

Em relação aos benefícios da ação para a comunidade envolvida, observou-se que a proposta foi bem recebida desde o princípio pela direção da escola e pelos alunos que concluíram a oficina e indicaram que gostariam de participar de outras edições. A avaliação positiva desta experiência em relação a equipe interinstitucional e o formato curto ( 2 encontros) da oficina com o desenvolvimento de um aplicativo de perguntas e respostas possibilitou o planejamento e execução de uma ação conjunta de longo prazo, durante o ano de 2017, no qual serão ministradas oito oficinas que irão abranger todas as escolas de ensino médio do município. Até o momento foram oferecidas duas oficinas. Além disso, está previsto o oferecimento de um curso de longa duração para os alunos que mais se destacarem nas oito oficinas oferecidas.

\section{Referências}

Finizola, A. et al. (2014). "O ensino de programação para dispositivos móveis utilizando o MIT-App Inventor com alunos do ensino médio". In: Anais do Workshop de Informática na Escola. 2014. p. 337.

Pereira Júnior. J. et al. (2005). "Ensino de algoritmos e programação: uma experiência no nível médio". In: XIII Workshop de Educação em Computação (WEI'2005). São Leopoldo, RS, Brasil.

Ribeiro, J., Manso, M. e Borges, M. (2016). "Dinâmicas com App Inventor no Apoio ao Aprendizado e no Ensino de Programação". In: Anais do Workshop de Informática na Escola. 2016. p. 271.

Vieira, M. e Alves, E. (2015). "Celular e sala de aula: dos limites às possibilidades". In: Anais do Workshop de Informática na Escola. 2015. p. 236. 